TITLE:

\title{
Enhanced production of ethyl pyruvate using gas-liquid slug flow in microchannel
}

\section{$\operatorname{AUTHOR}(\mathrm{S}):$}

Yasukawa, Toshiya; Ninomiya, Wataru; Ooyachi, Ken; Aoki, Nobuaki; Mae, Kazuhiro

\section{CITATION:}

Yasukawa, Toshiya ... [et al]. Enhanced production of ethyl pyruvate using gas-liquid slug flow in microchannel. Chemical Engineering Journal 2011, 167(2-3): 527-530

ISSUE DATE:

2011-03

URL:

http://hdl.handle.net/2433/157342

\section{RIGHT:}

(C) 2010 Elsevier B.V.; This is not the published version. Please cite only the published version.; この論文は出版社版でありません。引用の際に は出版社版をご確認ご利用ください。 
Enhanced production of ethyl pyruvate using gas-liquid slug flow in microchannel

Toshiya Yasukawa ${ }^{\mathrm{a}}$, Wataru Ninomiya ${ }^{\mathrm{a}}$, Ken Ooyachi $^{\mathrm{a}}$, Nobuaki Aoki ${ }^{\mathrm{b}}$, Kazuhiro Mae ${ }^{\mathrm{b},{ }^{*}}$

${ }^{a}$ Corporate Research Laboratories, Mitsubishi Rayon Co., Ltd., 20-1, Miyuki-Cho, Otake,

Hiroshima 739-0693, Japan

bepartment of Chemical Engineering, Graduate School of Engineering, Kyoto University,

Kyoto-daigaku Katsura, Nishikyo-ku, Kyoto 615-8510, Japan

*Corresponding author. Tel.: +81 75383 2668; fax: +81 753832658 .

E-mail address: kaz@cheme.kyoto-u.ac.jp (K. Mae). 


\section{Abstract}

The use of a gas-liquid slug flow in a microreactor has several advantages such as a large surface area for contacting gas and liquid phases and circulation flow inside slugs. These advantages accelerate the mass transfer between the two phases, resulting in a high concentration of dissolved gas. The enhanced mass transfer is useful in carrying out liquid phase oxidation that uses oxygen gas as the oxidizing agent. The gas-liquid slug flow in a microreactor system is applied to the oxidation of ethyl lactate using an oxy-vanadium species for producing ethyl pyruvate. The reactor system includes two T-shaped micromixers: one for mixing the substrate with a catalyst solution and the other for generating slug flow by the addition of oxygen. The oxidation reaction proceeds right after the slug flow is generated in the second mixer, because the substrate and the catalyst mix rapidly in the first micromixer. Moreover, a high concentration of dissolved oxygen due to improved mass transfer in slug flow increases the oxidation reaction rate. Therefore, compared to a batch reaction, the synthesis using slug flow provides high yields of ethyl pyruvate per unit time and achieves satisfactory productivity at the reaction temperature of $323 \mathrm{~K}$, which is lower than that employed in conventional syntheses. The proposed system enables the production of ethyl pyruvate using a simple reactor setup with reduced energy consumption.

Keywords: Slug flow; Mass transfer; Liquid phase oxidation; Pyruvate; Vanadium catalyst 


\section{Introduction}

Pyruvic acid and its derivatives such as ethyl pyruvate are used as intermediates for perfumes, food additives, and electronic materials [1]. They are also attractive as raw materials for various bioactive substances such as antivirus and anticancer drugs [2]. The production of pyruvic acid is still based on the conventional reaction scheme through dehydrative decarboxylation of tartaric acid. The scheme provides pyruvic acid in good yield but has a serious disadvantage of requiring an excess amount of $\mathrm{KHSO}_{4}$ (decarboxylation agent) per batch [3,4]. Therefore, a new process with a high atom efficiency for the production of pyruvic acid should be developed. Pyruvic acid can also be synthesized by using two methods in which lactic acid is used as the raw material. The first method is a gas phase process with a solid catalyst. The substrate is vaporized in this process. This process has been improved with the development of various catalysts, for example, binary oxides containing molybdenum such as $\mathrm{Fe}_{2} \mathrm{O}_{3}-\mathrm{MoO}_{3}$ and $\mathrm{TeO}_{2}-\mathrm{MoO}_{3}$ [5], vanadium oxide species [6], and iron phosphate [7-9]. Although this process can be used to obtain high productivity of pyruvate from lactate, the process requires a reaction temperature of $473-573 \mathrm{~K}$ to vaporize lactate as a starting material, leading to a large running cost. The second method is a liquid phase reaction with a solid catalyst. Unlike in a gas phase process, a substrate reacts in a liquid phase process. The reaction catalyzed by Pd-Metal alloys supported on activated carbon 
has been performed in a milder condition such as reaction temperature less than $363 \mathrm{~K}[10,11]$.

However, because catalysts for the liquid phase reaction are expensive, there is a need to develop an inexpensive catalyst.

On the basis of this discussion, a process using an inexpensive catalyst that requires a reaction temperature of less than $373 \mathrm{~K}$ is necessary, for improving the productivity of pyruvic acid. Oxidation of ethyl lactate using an inexpensive vanadium species as a catalyst can serve this purpose. Because the yield of the product, ethyl pyruvate, depends on the concentration of dissolved oxygen, the efficient transfer of oxygen into the liquid phase containing the substrate is essential to achieve high productivity. Gas-liquid slug flow in a microreactor accelerates mass transfer between the two phases owing to the large surface area for contacting gas and liquid phases and circulation flow inside slugs. Near the interface of the two phases, the internal circulation flow renews the fluid and solute concentration. The flow preserves the difference between the interface and equilibrium concentrations, namely the driving force for the mass transfer, resulting in an enhanced transfer [12]. Therefore, efficient production of pyruvic acid is possible by combining the oxidation using vanadium catalyst and the slug flow in microchannels.

In this study, we propose a microreactor system based on gas-liquid slug flow for the efficient production of pyruvate from the lactate derivative. The reaction scheme is shown in Fig. 1. We examine the validity of this system for the reaction system of lactate to pyruvate 
under moderate temperature conditions and extract the rate constant of this reaction.

\section{Experimental}

\subsection{Batch reaction}

The oxidation of ethyl lactate ( 2 mmol, Wako Pure Chemical) was carried out in a flask containing vanadium oxychloride $\left(\mathrm{VOCl}_{3}, 0.13 \mathrm{mmol}\right.$, Wako Pure Chemical), molecular sieve-3A (1.0 g, Wako Pure Chemical), and dry acetonitrile (10 mL, KANTO CHEMICAL) as a solvent at room temperature $(298 \mathrm{~K})$. The oxidizing gas was filled in the flask with an aspirator and a balloon filled with the agent. The interfacial area between the gas and the liquid phases was $18-20 \mathrm{~cm}^{2}$. Oxygen in air or pure oxygen gas was used as an oxidizing agent. The time for reaction under air was 20 min (entry 1), and that for reaction under oxygen was 13 min (entry 2) and 20 min (entry 3). The liquid in the flask was stirred at 450 rpm. After quenching the reaction by adding distilled water $(10 \mathrm{~mL})$, the ethyl lactate and pyruvate were extracted using ethyl acetate $(10 \mathrm{~mL})$. The conversion of ethyl lactate and the yield of ethyl pyruvate were determined using a gas chromatograph (GC-2014, Shimadzu).

\subsection{Flow reaction}


Fig. 2 illustrates a schematic of the experimental setup for a microreactor system based on gas-liquid slug flow. The proposed system is easy to construct because the tubing and joints are commercially available. All solutions have been fed with high performance liquid chromatography (HPLC) pumps, and the flow rate of the oxidizing agent is controlled using a flow meter. The system consists of two mixing zones. In the first mixing zone, ethyl lactate in acetonitrile $\left(0.2 \mathrm{~mol} \cdot \mathrm{L}^{-1}\right)$ and $\mathrm{VOCl}_{3}$ in acetonitrile $\left(0.02 \mathrm{~mol} \cdot \mathrm{L}^{-1}\right)$ are mixed. The flow rate of each solution is $1 \mathrm{~mL} \cdot \mathrm{min}^{-1}$. This zone consists of a $1 / 16$ union tee (inner diameter: $1.3 \mathrm{~mm}$, Swagelok) and a 1/16"-outer-diameter PTFE tube. The tube length is 300 $\mathrm{mm}$. The inner diameter (i.d.) of the tube is $1.0 \mathrm{~mm}$ or $0.5 \mathrm{~mm}$. We call the system with the tube of i.d. $1.0 \mathrm{~mm}$ "Flow reaction 1" and that with the tube of i.d. $0.5 \mathrm{~mm}$ "Flow reaction 2". In the second mixing zone, oxygen gas $\left(2 \mathrm{~mL} \cdot \mathrm{min}^{-1}\right)$ and the liquid mixture are mixed, and gas-liquid slug flow is formed in the reaction zone. The initial gas to liquid volume ratio is 1 . This zone consists of a 1/16 inch union tee (inner diameter: $1.3 \mathrm{~mm}$, Swagelok) and a $1 / 16$ "-outer-diameter PTFE tube. The tube length is $5-20 \mathrm{~m}$; its inner diameter is $1.0 \mathrm{~mm}$. The initial slug length of both, the gas and the liquid was 5.0-6.0 $\mathrm{mm}$. The mean residence time in the second mixing zone (reaction time) ranged from 1 min to 3.75 min by changing the length of the channel. The molar ratio of ethyl lactate and oxygen atom $\left(F_{\mathrm{O}} / F_{\text {Lactate }}\right)$ is 0.89 . This value is less than the stoichiometric ratio, that is, 1 . Therefore, in this study, all experiments 
were carried out under the condition that $\mathrm{O}_{2}$ was not exhausted. The maximum range of ethyl lactate conversion was $60 \%$. Both mixing zones were kept at room temperature (298 K). The reactor outlet was under atmospheric pressure.

The effects of reaction temperature were also examined. The reaction temperatures were 293 (Flow reaction 3), 308 (Flow reaction 4), or $323 \mathrm{~K}$ (Flow reaction 5). For the temperature dependency investigation, the inner diameter of the first mixing zone was $0.5 \mathrm{~mm}$, and the catalyst flow rate was $1.0 \mathrm{~mL} \cdot \mathrm{min}^{-1}\left(0.01 \mathrm{mmol} \cdot \mathrm{min}^{-1}\right)$.

For all experiments of the flow reaction, the reaction liquid was sampled in a vial containing distilled water. The ethyl lactate and pyruvate were extracted using ethyl acetate and were quantified using a gas chromatograph (GC-2014, Shimadzu).

The reaction mixture of this oxidation catalyzed vanadium species with an oxidizing agent were analyzed using a gas chromatograph-mass spectrometer (GC-1700, Shimadzu). From this analysis, ethyl pyruvate, acetic acid and unreacted ethyl lactate were detected. However, in all experimental conditions of our studies, the amount of acetic acid was less than $1 \%$ of the total amount of ethyl lactate and ethyl pyruvate. In this analysis, byproducts via hydrolysis of ethyl ester, such as lactic acid, pyruvic acid, and ethanol, were not detected. Thus, the ethyl lactate conversion was approximately equal to the pyruvate yield. 


\section{Results and discussion}

\subsection{Superiority of flow reaction compared with batch reaction}

The result of batch reaction using air or oxygen gas as the oxidizing agent is summarized in Table 1. The yield of ethyl pyruvate using pure oxygen was higher than that using air. This tendency indicates that the dissolved oxygen concentration in the solution affects the productivity of ethyl pyruvate. This tendency is justified using the reaction mechanism. Fig. 3 shows a plausible mechanism for ethyl pyruvate formation using vanadium catalyst [13]. On the basis of this mechanism, first a vanadium species reacts with both alcohol (ethyl lactate) and oxygen to form $\mathrm{VO}_{2} \mathrm{X}$ species. $\mathrm{X}$ are anionic ligands such as $\mathrm{Cl}^{-}$ and $\mathrm{OH}^{-}$. The initial species of vanadium is $\mathrm{VOCl}_{3}$, and after this species reacts with ethyl lactate and $\mathrm{O}_{2}, \mathrm{VO}_{2} \mathrm{Cl}$ is formed. However, $\mathrm{VO}_{2} \mathrm{OH}$ via ligand exchange with $\mathrm{H}_{2} \mathrm{O}$ is also possible. The species further reacts with other alcohols (ethyl lactate) to form a vanadium alcolate. The product carbonyl compound (ethyl pyruvate) and dihydroxyvanadium species is then formed via $\beta$-hydrogen elimination from vanadium alcolate. The subsequent dehydration of the dihydroxyvanadium species due to oxidation with oxygen reproduces $\mathrm{VO}_{2} \mathrm{X}$ species. Thus, oxygen affects several steps of the mechanism, and the suggested reaction mechanism supports this tendency. 
Fig. 4 shows the result of Flow reaction 1. The ethyl pyruvate yield of Flow reaction 1 was higher than that of the batch reaction in spite of the fact that the reaction time of flow reaction is shorter. This result suggests that the observed reaction rate of the flow reaction increases in comparison with that of the batch reaction. The accelerated rate is attributed to the high dissolved oxygen concentration. Such high concentration is achieved because of the feature of gas-liquid slug flow in a micro reactor, that is, rapid mass transfer between two phases through internal circulation flow and large interfacial surface area between gas and liquid.

\subsection{Effect of changing diameter of first mixing zone}

The results of Flow reactions 1 and 2 are shown in Fig. 5. When the residence time is less than $33 \mathrm{~s}$ for Flow reaction 1, no pyruvate is produced. Thus, there is an induction period before the formation of pyruvate starts. Incomplete mixing of ethyl lactate and $\mathrm{VOCl}_{3}$ solutions induces the induction period. For Flow reaction 2, because the slope of the ethyl pyruvate yield against the reaction time is comparable, the reaction rate after the induction period is also equivalent. However, the induction period of Flow reaction 2 is shorter than that of Flow reaction 1. This is because the inner diameter of the first mixing zone of Flow reaction 1 is smaller than that of Flow reaction 2, resulting in an accelerated mixing of ethyl 
lactate and $\mathrm{VOCl}_{3}$ solutions.

\subsection{Temperature dependency of flow reaction}

Fig. 6 shows the relation between the yield of ethyl pyruvate and the reaction time for various reaction temperatures. The yield increases with a rise in temperature. The ethyl pyruvate yield using slug flow at $323 \mathrm{~K}$ per unit time was 12 times higher than the batch reaction yield per unit time. The improved reaction rate shows that the mass transfer of oxygen to liquid phase is fast for the reactions at $308 \mathrm{~K}$ and $323 \mathrm{~K}$.

Using the results in this section, we then analyze the kinetics of this reaction system.

We have assumed that the overall reaction rate $r$ (production rate of ethyl pyruvate) is expressed by the rate constant for reaction $k$, the concentration of ethyl lactate $\left(C_{\mathrm{EL}}\right)$, and the concentration of dissolved oxygen $\left(C_{\mathrm{O} 2}\right)$.

$$
r=k C_{\mathrm{EL}} C_{\mathrm{O} 2}
$$

In eq. (1), $k$ and $C_{\mathrm{O} 2}$ are variables depending on temperature. We have also assumed that because the mass transfer of oxygen is sufficiently rapid, the dissolved oxygen concentration is equal to the equilibrium value. With this assumption, $C_{\mathrm{O} 2}$ is determined in accordance with its solubility and kept constant at a fixed temperature. In this assumption, the overall reaction rate in eq. (1) is first-order reaction with respect to ethyl lactate, and the dissolved oxygen 
concentration is determined by temperature. Thus, eq. (1) can be rewritten by the following expression:

$$
r=K_{T} C_{\mathrm{EL}}
$$

where $K_{T}$ is variable depending on temperature $T[\mathrm{~K}]$. As a result, the reaction rate depends on $C_{\mathrm{EL}}$ and the temperature dependence parameter $K_{T}$. Next, for comparing the values of $K_{293}$, $K_{308}$, and $K_{323}, \ln \left(C_{\text {E.L }}\right)$ was plotted against reaction time (Fig. 7). The plots of each temperature lie in straight lines. This confirms that this reaction is of the first order in terms of ethyl lactate. The ratio of absolute value of each slope shown in Fig. 7 is

$K_{293}: K_{308}: K_{323}=1.00: 1.55: 2.84$

Form these slopes, the values of $K_{T}$ were determined. An Arrhenius plot using $K_{T}$ gives a straight line (Fig. 8). Therefore, the overall activation energy is calculated from the slope. The overall activation energy was $33.4 \mathrm{~kJ} \cdot \mathrm{mol}^{-1}$.

\section{Conclusion}

For developing an efficient process of pyruvate production, we have proposed a microreactor system based on gas-liquid slug flow and examined its effectiveness. The reactor system includes two T-shape micromixers: one for mixing the substrate with the catalyst solution and the other for generating slug flow by the addition of oxygen. The proposed 
system is easy to construct because the tubing and joints are commercially available. The results show that the oxidation of ethyl lactate using oxygen gas in the microreactor system proceeds efficiently in a moderate reaction temperature less than and equal to $323 \mathrm{~K}$, which is lower than that applied in conventional syntheses. The reaction is accelerated by enhanced mass transfer of slug flow. Moreover, the rapid mixing provided by the micromixer and the rise in reaction temperature improves the productivity of ethyl pyruvate by 12 times compared with the productivity achieved in a batch reaction. The enhanced reaction rate lowers the reaction temperature and the energy used compared with a batch reaction giving an equivalent productivity. From these results, we conclude that the proposed microreactor system enables efficient production of ethyl pyruvate under moderate temperature using an inexpensive catalyst and is suitable for the catalytic oxidation of ethyl lactate. 


\section{References}

[1] A. Corma, S. Iborra, A. Velty, Chemical routes for the transformation of biomass into chemicals, Chem. Rev. 107 (2007) 2411-2502.

[2] T. Iida, Y. Ohira, 7-fluoro-2,3-didehydrosialic acid and intermediate for synthesis thereof, WO1995032955 (1995).

[3] E. Erlenmeyer, Verhalten der Glycerinsäure und der Weinsäure gegen wasserentziehende Substanzen, Ber Dtsch Chem. Ges, Vol.14 (1881) 320-323.

[4] F. Howard, PYRUVIC ACID, Org. Syn. Coll. Vol.1 (1941) 475-476.

[5] S. Sugiyama, N. Shigemoto, N. Masaoka, S. Sugetoh, H. Kawami, K. Miyaura, H. Hayashi, Vapor-phase oxidation of ethyl lactate to pyruvate over various oxide catalysts, Bull. Chem. Soc. Jpn. 66 (1993) 1542-1547.

[6] B. V Sovorov, S. R. Rafikov, A. D. Kagarlitskii, The oxidative ammonolysis of organic compounds, Russ. Chem. Rev. 34 (1965) 657-668.

[7] M. Ai, K. Ohdan, Effects of differences in the structures of iron phosphates on the catalytic action in the oxidative dehydrogenation of lactic acid to pyruvic acid, Appl. Catal. A 165 (1997) 461-465.

[8] M. Ai, K. Ohdan, Oxidation by iron phosphate catalyst, J. Mol. Catal. A 159 (2000) 
$19-24$.

[9] M. Ai, Catalytic activity of iron phosphate doped with a small amount of molybdenum in the oxidative dehydrogenation of lactic acid to pyruvic acid, Appl. Catal. A 234 (2002) 235-243.

[10] T. Tsujino, S. Ohigashi, S. Sugiyama, K. Kawashiro, H. Hayashi, Oxidation of propylene glycol and lactic acid to pyruvic acid in aqueous phase catalyzed by lead-modified palladium-on-carbon and related systems, J. Mol. Catal. 71 (1992) 25-35.

[11] S. Sugiyama, T. Kikumoto, H. Tanaka, K. Nakagawa, K. Sotowa, K. Maehara, Y. Himeno, W. Ninomiya, Enhancement of catalytic activity on $\mathrm{Pd} / \mathrm{C}$ and $\mathrm{Te}-\mathrm{Pd} / \mathrm{C}$ during the oxidative dehydrogenation of sodium lactate to pyruvate in an aqueous phase under pressurized oxygen, Catal. Lett. 131 (2009) 129-134

[12] Y. Okubo, T. Maki, N. Aoki, T.H. Khoo, Y. Ohmukai, K. Mae, Liquid-liquid extraction for efficient synthesis and separation by utilizing micro spaces, Chem. Eng. Sci. 63 (2008) 4070-4077.

[13] Y. Maeda, N. Kakiuchi, S. Matsumura, T. Nishimura, T. Kawamura, S. Uemura, Oxovanadium complex-catalyzed aerobic oxidation of propargylic alcohols, J. Org. Chem. 67 (2002) 6718-6724. 


\section{Table and Figure Captions}

Fig. 1. Liquid-phase oxidation of lactate derivative to pyruvate under oxygen.

Fig. 2. Experimental setup for flow reaction.

Fig. 3. Reaction mechanism related to oxygen conversion.

Fig. 4. Comparison of flow and batch reactions at room temperature. • Flow reaction 1.

Batch reaction using pure oxygen as oxidizing agent.

Fig. 5. Effects of inner diameter of the first mixing zone. $\bullet$ Flow reaction 1, inner diameter of the first mixing zone: $1 \mathrm{~mm}$. $\Delta$ Flow reaction 2, inner diameter of the first mixing zone: 0.5 $\mathrm{mm}$.

Fig. 6. Temperature dependency of ethyl pyruvate yield ( $\boldsymbol{\Delta}$ Flow reaction 3 at $298 \mathrm{~K}$. $\mathbf{\text { Flow }}$ reaction 4 at $308 \mathrm{~K}$. • Flow reaction 5 at $323 \mathrm{~K}$ ).

Fig. 7. Plots for determining rate constants.

Fig. 8. Arrhenius plot.

Table 1. Batch reaction at room temperature under air or oxygen 
<smiles>CCC(=O)OC(=O)C(=O)OC(=O)C(=O)O</smiles>

Fig. 1. Liquid-phase oxidation of lactate derivative to pyruvate under oxygen. 


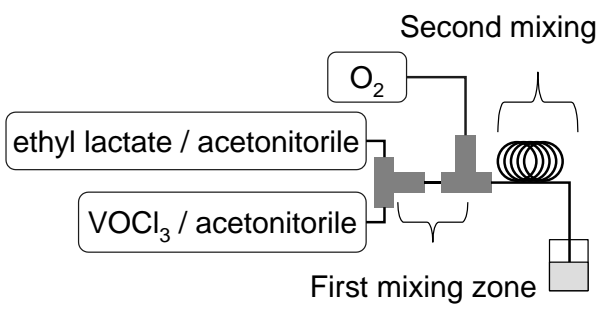

Fig. 2. Experimental setup for flow reaction. 


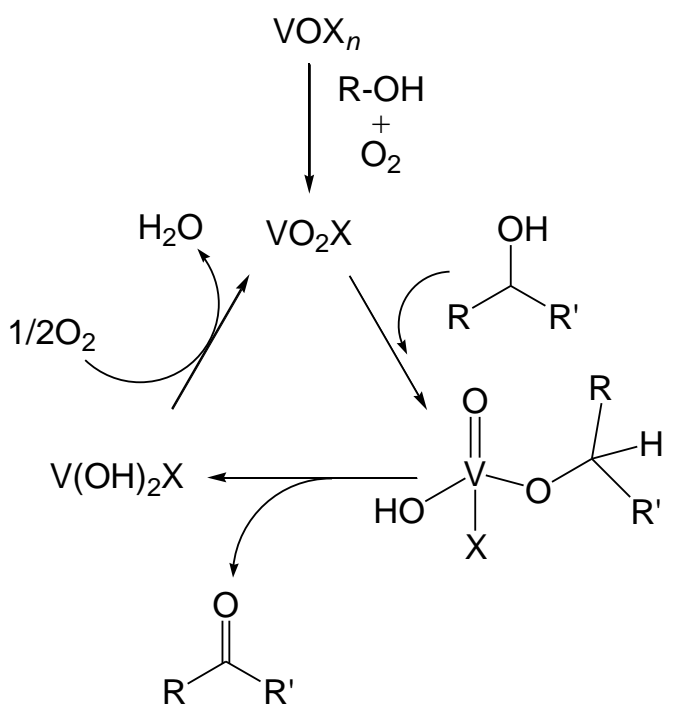

Fig. 3. Reaction mechanism related to oxygen conversion. 


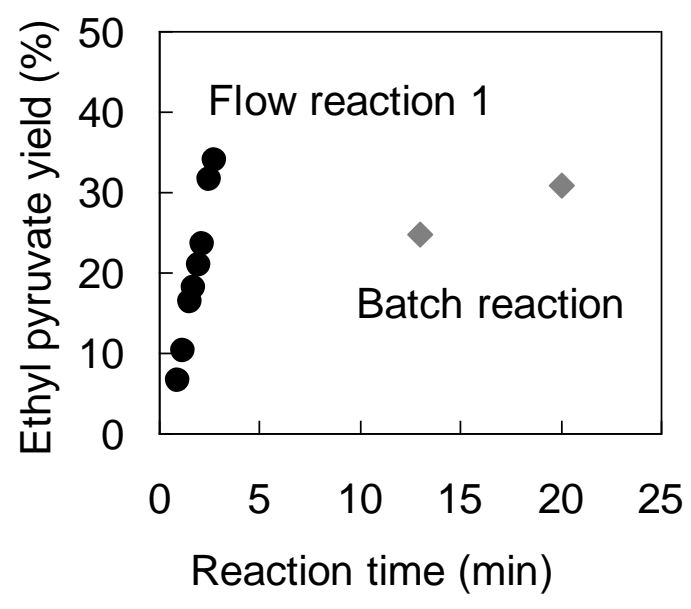

Fig. 4. Comparison of flow and batch reactions at room temperature. • Flow reaction 1. Batch reaction using pure oxygen as oxidizing agent. 


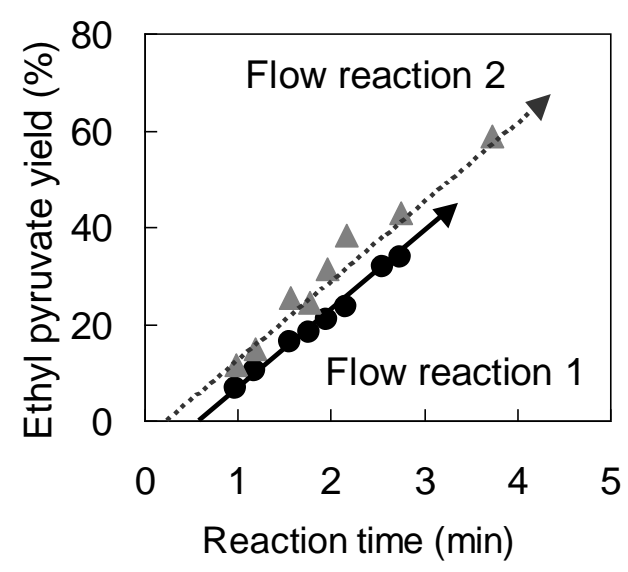

Fig. 5. Effects of inner diameter of the first mixing zone. $\bullet$ Flow reaction 1, inner diameter of the first mixing zone: $1 \mathrm{~mm}$. $\Delta$ Flow reaction 2, inner diameter of the first mixing zone: 0.5 $\mathrm{mm}$. 


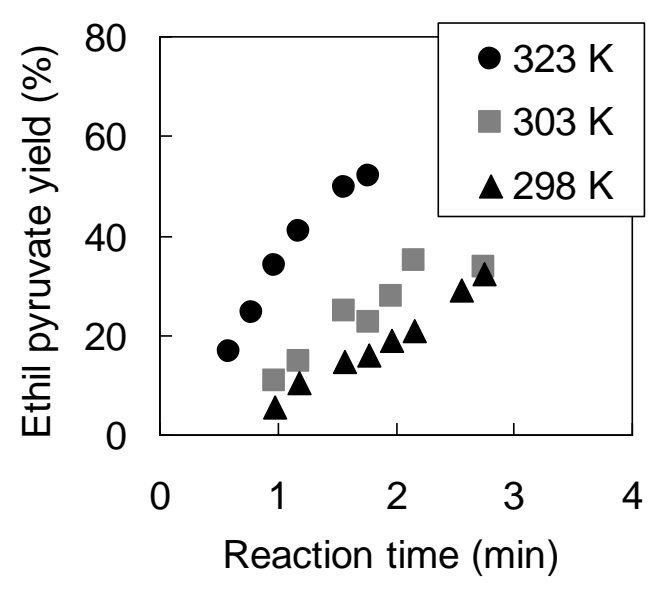

Fig. 6. Temperature dependency of ethyl pyruvate yield ( $\Delta$ Flow reaction 3 at 298 K. a Flow reaction 4 at $308 \mathrm{~K}$. $\bullet$ Flow reaction 5 at $323 \mathrm{~K}$ ). 


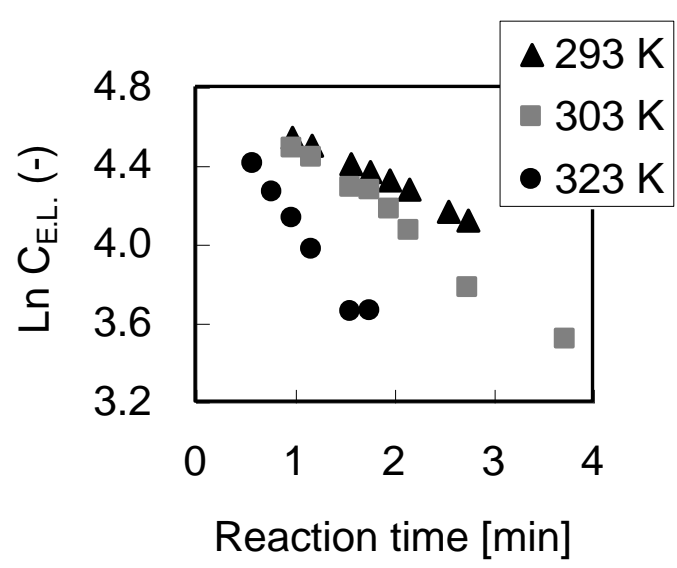

Fig. 7. Plots for determining rate constants. 


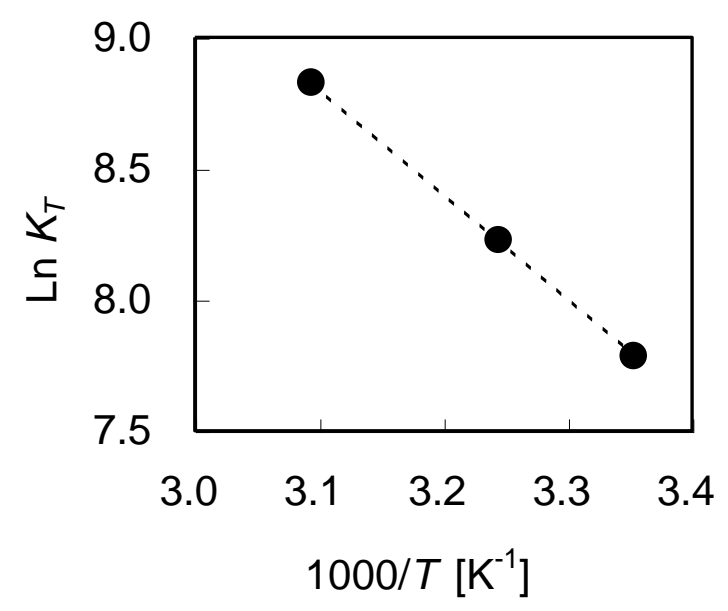

Fig. 8. Arrhenius plot. 
Table 1

Batch reaction at room temperature under air or oxygen

\begin{tabular}{ccccc}
\hline \multirow{2}{*}{ Entry } & Oxidizing & Time & Ethyl lactate & Ethyl pyruvate \\
& agent & {$[\mathrm{min}]$} & Conv. [\%] & Yield [\%] \\
\hline \hline 1 & Air & 20 & 23.6 & 21.6 \\
2 & $\mathrm{O}_{2}$ & 13 & 25.7 & 24.8 \\
3 & $\mathrm{O}_{2}$ & 20 & 31.5 & 30.8 \\
\hline
\end{tabular}

